\title{
Novel fluorescent amphiphilic block copolymers: photophysics behavior and interactions with DNA
}

\author{
X. J. Lu, L. Z. Meng*, X. X. Zhong \\ Department of Chemistry, Wuhan University, Wuhan 430072, P. R. China
}

Received 23 March 2007; accepted in revised form 5 May 2007

\begin{abstract}
In this study, novel amphiphilic fluorescent copolymers poly(N-vinylpyrrolidone)- $b$-poly(N-methacryloyl-N'( $\alpha$-naphthyl)thiourea) (PVP- $b$-PNT) were synthesized via ATRP with poly(N-vinylpyrrolidone)-Cl as macroinitiator and N-methacryloyl-N'- $\alpha$-naphthylthiourea (NT) as hydrophobic segment. PVP- $b$-PNT copolymers were characterized by ${ }^{1} \mathrm{H}$ NMR, GPC-MALLS and fluorescence measurements. The aggregation behavior of PVP- $b$-PNT in water was investigated by transmission electron microscope (TEM) and dynamic light scattering (DLS) measurement. The photophysics behavior of PVP- $b$-PNT showed that block copolymer formed strong excimer. The interaction of DNA with the block copolymer made the excimer of block copolymer quench. The cytotoxicity result of PVP- $b$-PNT in cell culture in vitro indicated that this copolymer PVP- $b$-PNT had good biocompatibility.
\end{abstract}

Keywords: biocompatible polymers, block, fluorescence, excimer

\section{Introduction}

Amphiphilic block and graft copolymers consisting of hydrophilic and hydrophobic segments are selfassembling materials, which are capable of forming polymer assemblies, micelles, and vesicles in aqueous solutions, and have been used extensively in both research and technology [1, 2]. Amphiphilic block copolymers are also very attractive polymers as carriers for the controlled delivery of drugs due to their water soluble part and hydrophobic part $[3,4]$.

Fluorescent polymers are gaining increased attention due to their high sensitivity and ease of measurement. For example, conjugated polymer chemosensors have recently been used with great success for the detection of a range of analytes from biomolecules to explosives [5]. Fluorescent polymers have several advantages over small molecule sensors due to enhancements associated with electronic communication between receptors along the polymer backbone, processability, and ease of structural modification.

Photophysical studies on fluorescent polymers in confined environments play a vital role in many natural and biological processes. The behavior of polymers in solution can be studied by attaching labels of various types, and inferring motion or location of the polymer from the label. Fluorescent labels have been employed using special shape, position or depolarization of light to obtain information about the macromolecule [6]. In aqueous media, amphiphilic copolymers self-organized into micelles which are one of organized environments. The most important property of such compartmentalized micellar media is that they have the ability to concentrate guest molecules into relatively small effective volumes and then to promote the reencounter of such molecules [7]. This property also makes them a good device for inducing efficient electrostatic interactions between the micelle head groups and the guest molecules as well as strong

*Corresponding author, e-mail: lzhmeng@whu.edu.cn

(C) BME-PT and GTE 
hydrophobic interactions of these molecules with the micelle chains.

Poly(N-vinylpyrrolidone) (PVP) is a very interesting polymer because it is well water-soluble, biocompatible and has been extensively used in pharmaceutical industry [8]. Recently, PVP can be found in various drug delivery systems, including microspheres, nanoparticles, liposomes, and polymer conjugates. The researches of amphiphilic PVP copolymer used as a promising fluorescent probe for measurements of biomacromolecules [9] and a promoter for enhancement of DNA amplification by polymerase chain reaction [10] were investigated.

In our case, we preferred amphiphilic fluorescent copolymer that had a good biocompatiblity and well-defined structure. Atom transfer radical polymerization (ATRP) is an extremely active area of polymer synthesis research [11]. From this point of view we have prepared well-defined PVP by ATRP. The resulting product has a controlled molecular weight and narrow molecular weight distribution. In this contribution novel amphiphilic fluorescent copolymers poly(N-vinylpyrrolidone)$b$-poly(N-methacryloyl-N'-( $\alpha$-naphthyl) thiourea) (PVP- $b$-PNT) were synthesized via ATRP with PVP-Cl as macroinitiator and N-methacryloyl-N'$\alpha$-naphthylthiourea (NT) as hydrophobic segment. The photophysics behavior of the amphiphilic block copolymers was investigated by fluorescent measurements in detail. The major application of the fluorescent polymer in aqueous media was used in the field of biological molecules, so the interaction of the block copolymer with DNA was described and the cytotoxicity of the copolymers in vitro were also evaluated. The results showed that the copolymers exhibited exquisite fluorescence property and good biocompatibility.

\section{Experimental section}

\subsection{Materials}

N-Vinylpyrrolidone (VP, Acros, 99\%) was purified by distillation under reduced pressure to remove the inhibitors before use. $\mathrm{CuCl}$ (Aldrich, 98\%) was purified by stirring in acetic acid, washed with methanol, and then dried in vacuum. Methacryloyl chloride was prepared by refluxing a mixture of thionyl chloride and methacrylic acid, followed by distillation. $\mathrm{CuCl}_{2}$ (Aldrich, 99.9\%), 2,2'-bipyri- dine (bpy, Acros, 99\%), methyl 2-chromopropionate (MCP, Aldrich, 97\%) and N, N-dimethylformamide (DMF, Acros, HPLC grade) were used as received without further purification. Plasmid pBR322 DNA was from Huamei Biological Engineering Company. $\alpha$-Naphthylamine, basic alumina and all other reagents were from Shanghai No.1 Chemical Reagent Factory and used as received without further purification.

\subsection{Preparation of $N$-methacryloyl-N'-( $\alpha$ - naphthyl) thiourea (NT)}

KSCN (17.05 g, $0.175 \mathrm{mmol})$ was dissolved in $150 \mathrm{ml}$ of anhydrous acetonitrile and the solution was then cooled by an ice-salt bath. Under stirring methacryloyl chloride $(14.4 \mathrm{ml}, 0.15 \mathrm{~mol})$ was added dropwise into it. And then the reaction was allowed to stir for $5 \mathrm{~h}$ at room temperature. The precipitated $\mathrm{KCl}$ was removed by filtration. $\alpha$ Naphthylamine (18.61 g, $0.13 \mathrm{~mol}$ ) was dissolved in $60 \mathrm{ml}$ of acetonitrile and added dropwise into the above filtrate with stirring at room temperature. The system turned to yellow from dark red and began to precipitate rapidly. After being filtrated and washed with water, the yellow precipitate was vacuum-dried. The solid was dissolved in acetone and subsequently a large excess of cold water was added to give crystalline NT, yield: $75 \%$; mp: $135-137^{\circ} \mathrm{C} .{ }^{1} \mathrm{H}$ NMR $\left(300 \mathrm{MHz}, \mathrm{CDCl}_{3}\right): \delta(\mathrm{ppm})$ 12.53 and 8.88 (each s, 1H, 2NH), 7.19-7.93 (m, $7 \mathrm{H}, \mathrm{ArH}$ ), 5.99 and 5.67 (each $\left.\mathrm{m}, 1 \mathrm{H}, \mathrm{CH}_{2}=\right), 2.05$ (s, $3 \mathrm{H}, \mathrm{CH}_{3}$ ). Elemental analysis: Calcd for $\mathrm{C}_{15} \mathrm{H}_{14} \mathrm{~N}_{2} \mathrm{OS}$ [\%]: C, 66.64; H, 5.22; N, 10.36; S, 11.86. Found [\%]: C, 66.59; H, 5.30; N, 10.28; S, 11.78. ESI-MS (in $\mathrm{CH}_{3} \mathrm{CN}$ ): $\mathrm{m} / z(R I): 271\left(\mathrm{M}^{+}+1\right.$, 100) [12].

\subsection{Preparation of amphiphilic block copolymer by ATRP}

Amphiphilic block copolymers PVP- $b$-PNT were synthesized by ATRP in DMF. Macroinitiator PVP-Cl (target DP = 250) was synthesized according to the procedure for the polymerization of VP [13]. The $M_{n}$ was $18600 \mathrm{~g} / \mathrm{mol}$ and PDI was 1.26 by GPC-MALLS in DMF. In a typical run, a $25 \mathrm{ml}$ round-bottom flask was charged with DMF $(5 \mathrm{ml})$, NT, macroinitiator PVP-Cl and catalyst $\mathrm{CuCl} / \mathrm{bpy}$ with the following relative molar ratio NT:PVP-Cl: $\mathrm{CuCl}$ :bpy $=20: 1: 1: 2$ (i. e. target $\mathrm{DP}=20$ ). The 
flask was sealed with a rubber septum and evacuated and back-filled with nitrogen for three times. The flask placed in a preheated oil bath was kept at $60^{\circ} \mathrm{C}$ for $24 \mathrm{~h}$. Then the reaction mixture was diluted with $\mathrm{CHCl}_{3}$ and passed through a basic alumina column to remove ATRP catalyst. The resulting solution was then concentrated and the copolymer was precipitated into excess diethyl ether. The obtained copolymer was dried under vacuum to provide PVP- $b$-PNT-III. This protocol was repeated with varying the molar ratios of NT to PVP-Cl to obtain more water-soluble amphiphilic block copolymer PVP- $b$-PNT-I and II.

\subsection{Instruments}

All ${ }^{1} \mathrm{H}$ NMR spectra were recorded on a Varian Mercury VX-300 MHz spectrometer (USA). Elemental analysis was conducted on a Flash EA 1112 series elemental autoanalyzer (Italy). Mass spectra were obtained on an LCQ-Advantage electrospray ionization-mass spectrometer (ESI-MS) (Finnigan, England). Steady-state fluorescence spectra of copolymer solution were obtained on a Shimadzu RF-5301PC spectrometer (Japan) at room temperature. Gel permeation chromatography-multi-angle laser light scatting (GPC-MALLS) is convenient for determination of the true molecular weight and molecular weight distribution of polymer without standard sample. Number molecular weights $M_{n}$, and polydispersity $M_{w} / M_{n}$ of the samples were determined by a DAWN ${ }^{\circledR}$ DSP multi-angle laser photometer in DMF at a flow rate of $1.00 \mathrm{ml} / \mathrm{min}$ at $25^{\circ} \mathrm{C}$.

\subsection{Transmission electron microscope (TEM) observation}

The size and morphology of copolymer aggregates were recorded by a JEM-100CXII transmission electron microscope (Japan). The polymer solutions were placed onto the TEM copper grid covered by a polymer support film. After $15 \mathrm{~min}$, the excess solution was allowed to dry in atmosphere and at room temperature for $2 \mathrm{~h}$ before observation.

\subsection{Dynamic light scattering observation}

Dynamic light scattering (DLS) was used for the determination of particle size in water. For this analysis, a series of aqueous solutions of PVP- $b$ -
PNT with concentration of $2 \mathrm{~g} / \mathrm{l}$ were prepared by dissolving the polymer directly in water. Each measurement was carried out in triplicate at $25^{\circ} \mathrm{C}$ at an angle of $90^{\circ} \mathrm{C}$. The size distribution of particles and the intensity of mean size were recorded.

\subsection{In vitro cytotoxicity test}

The cytotoxicity of PVP- $b$-PNT was evaluated by using the MTT assay according to the method of Mosmann [14]. 5000 A549 cells/well, MTT solution $2.0 \mathrm{~g} / \mathrm{l}$ and Hank's balanced salt solution (HBSS) as a medium were selected to carry out the cytotoxicity tests. The test was performed as follows: after A549 cells were attached to the 96 wells and incubated for $24 \mathrm{~h}$ at $37^{\circ} \mathrm{C}$, the different concentration of PVP- $b$-PNT dissolved in HBSS were added to the wells. To each well $50 \mu$ of MTT solution was added after the wells were incubated for another $72 \mathrm{~h}$ at $37^{\circ} \mathrm{C}$. The plates were incubated for an additional $4 \mathrm{~h}$ at $37^{\circ} \mathrm{C}$ and the MTT solution was removed. Negative (HBSS) control wells were treated similarly as above. Absorbance was measured spectrophotometrically at $550 \mathrm{~nm}$ using a MuLTiskAn MK3 unit. Cell viability (as a percent of the negative control) was calculated from the absorbance values.

\section{Results and discussion}

\subsection{ATRP of PVP- $b$-PNT block copolymer}

Block copolymers were prepared via ATRP using the PVP-Cl as macroinitiator, NT as hydrophobic monomer and $\mathrm{CuCl} / \mathrm{bpy}$ complex as catalyst in DMF. Though a bpy-based catalyst is less active compared to tripodal amines and cyclic amines [11], the investigation on ATRP of acrylamide and dimethyl(1-ethoxycarbonyl)vinyl phosphate using $\mathrm{CuCl} /$ bpy as catalyst were reported $[15,16]$. So the bpy ligand was chosen to prepare PNT block. In this section, a series of well-defined block copolymers (PVP- $b$-PNT) with different hydrophobic segment is synthesized using the same PVP-Cl $\left(M_{n}=\right.$ 18600 , PDI $=1.26)$ via ATRP. The increase of molecular weight with conversion and relatively low PDI of the copolymers demonstrate the controllable characteristic of this polymerization.

The chemical composition of block copolymers is determined by ${ }^{1} \mathrm{H}$ NMR. A typical ${ }^{1} \mathrm{H}$ NMR spectrum of PVP- $b$-PNT-III in $\mathrm{CDCl}_{3}$ is shown in Fig- 


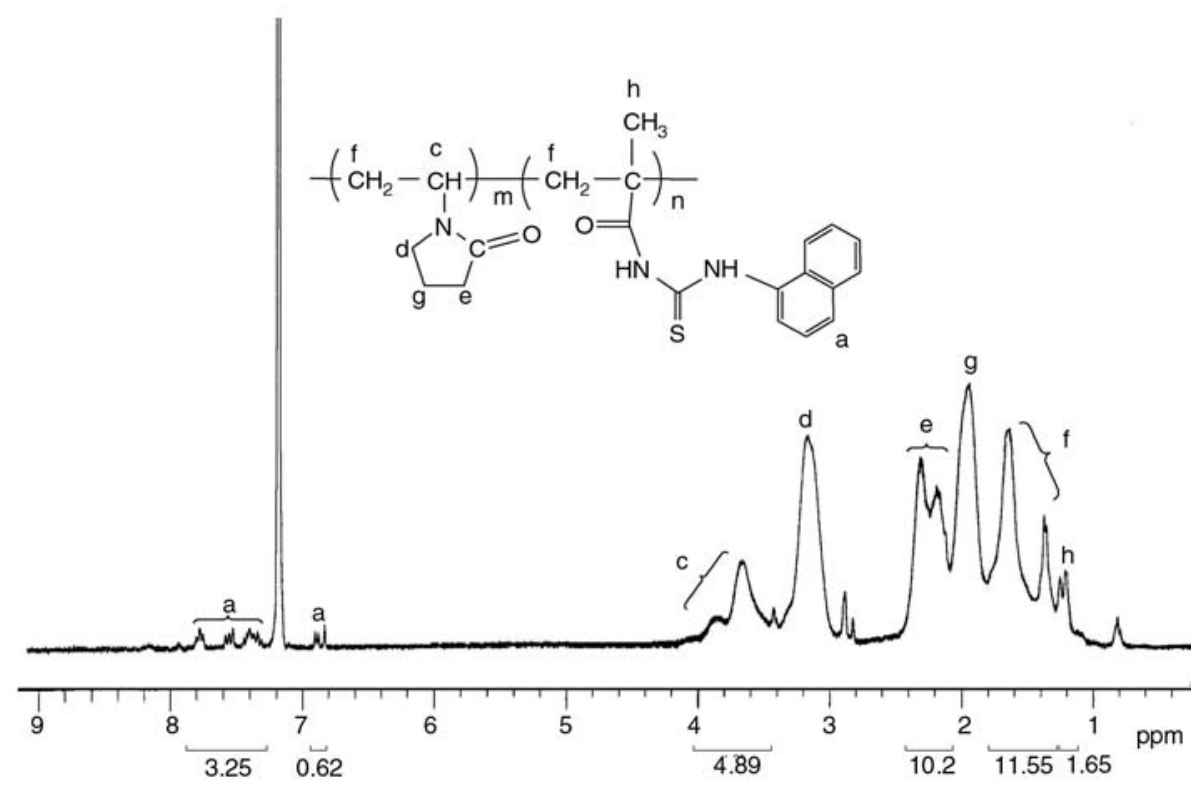

Figure 1. ${ }^{1} \mathrm{H}$ NMR spectrum of PVP- $b$-PNT-III in $\mathrm{CDCl}_{3}$

ure 1. The multiple of shift from 6.8 to 7.93 is attributed to the protons of the hydrophobic naphthyl groups of the block copolymer. The hydrophobic content is calculated from the relative integrated area of peak a corresponding to the protons of the naphthyl groups of the hydrophobic chains compared to that of peak c corresponding to the protons of $\mathrm{CH}-\mathrm{N}$ group in the hydrophilic backbone. The molecular weights of final copolymers were determined by GPC-MALLS in DMF.

The molecular weights of the block copolymers determined from ${ }^{1} \mathrm{H}$ NMR are consistent with those determined by GPC-MALLS in DMF and the molecular weight distributions are relatively low which are listed in Table 1. These results confirm that the molecular weight and the unit composition of block copolymers can be successfully controlled by varying the molar ratio of monomer to macroinitiator via sequential ATRP.

Table 1. Molecular characteristics of PVP- $b$-PNT

\begin{tabular}{|c|c|c|c|c|c|}
\hline \multirow{2}{*}{ Entry } & \multirow{2}{*}{$\begin{array}{c}\text { Yield }^{\mathbf{a}} \\
{[\%]}\end{array}$} & \multicolumn{2}{|c|}{ 1H NMR } & \multirow{2}{*}{$\begin{array}{c}M_{n}^{\mathbf{b}} \\
{[\mathrm{g} / \mathrm{mol}]}\end{array}$} & \multirow{2}{*}{$M_{w} / M_{n}^{b}$} \\
\hline & & PVP & PNT & & \\
\hline PVP-Cl & & 100 & 0 & 18600 & 1.26 \\
\hline PVP- $b$-PNT-I & 89 & 97 & 3 & 20000 & 1.33 \\
\hline PVP-b-PNT-II & 83 & 95 & 5 & 21300 & 1.32 \\
\hline PVP- $b$-PNT-III & 78 & 90 & 10 & 22500 & 1.38 \\
\hline
\end{tabular}

aYield of copolymer determined by gravimetric.

bNumber-average molecular weight and polydispersity in DMF by GPC-MALLS.

\subsection{Aggregation behavior of PVP- $b$-PNT in water}

The fluorescence emissions of PVP- $b$-PNT solution in aqueous show the same excimer emission in $\lambda_{\max }=448 \mathrm{~nm}$ in Figure 2. The intramolecular and intermolecular aggregations exist in all block PVP$b$-PNT in water even for that with the shortest hydrophobic block in copolymer backbone. A similar result was reported for pyrene labeled poly $(\mathrm{N}-$ isopropylacrylamide) [17].

In aqueous solution the PVP- $b$-PNT can orient themselves in a way that they expose their hydrophilic groups toward water and simultaneously protect their hydrophobic groups from the contact with water, and consequently they are able to form hydrophobic microdomains by inter- and intramol-

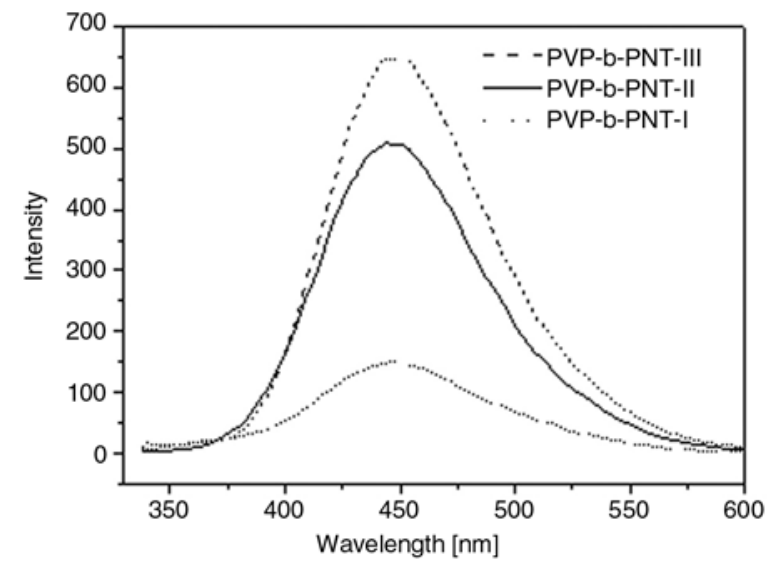

Figure 2. Fluorescence emission spectra of PVP- $b$-PNT solution at the concentration of $0.4 \mathrm{~g} / \mathrm{l}$ at $20^{\circ} \mathrm{C}$ excited at $330 \mathrm{~nm}$ 


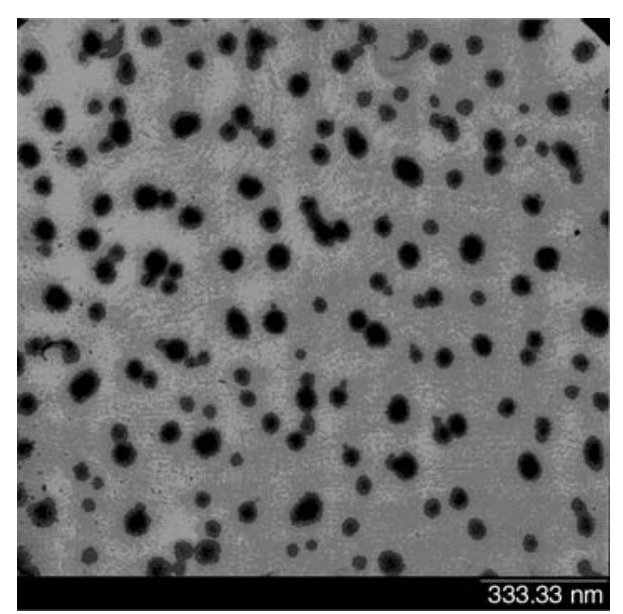

Figure 3. TEM of PVP- $b$-PNT-III aqueous solutions $2 \mathrm{~g} / 1$

ecular interactions. PVP- $b$-PNT micelles with short hydrophobic block in this case should have a coreshell structure.

The successful formation of micelles was confirmed by TEM measurement. Figure 3 shows the TEM image of the micelles formed by PVP- $b$ PNT-III copolymers. It can be seen that the micelles take a spherical morphology. Micelles composed of PVP- $b$-PNT-III in water at a concentration of $2 \mathrm{~g} / \mathrm{l}$ feature a single narrow size distribution with a mean diameter about $40 \mathrm{~nm}$. As a typical example, the particle size distribution of PVP- $b$-PNT-III micelles determined by dynamic light scattering is shown in Figure 4. Mean sizes of micelles formed by PVP- $b$-PNT-III copolymers are ca. $58 \mathrm{~nm}$ in diameter, which are much larger in the size than that observed by TEM in dried model.

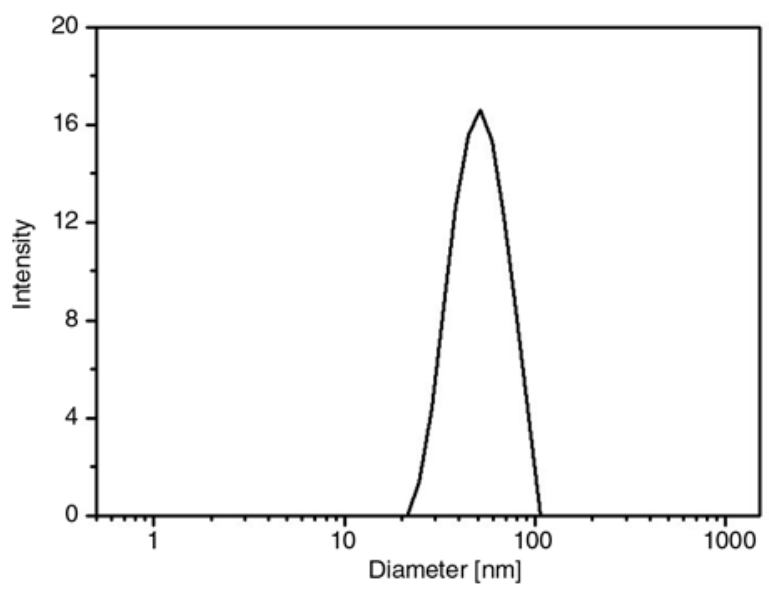

Figure 4. Size distribution of micells composed of PVP- $b$ PNT-III aqueous solutions $2 \mathrm{~g} / \mathrm{l}$ measured by DLS

\subsection{The effect of chain architecture on photophysics}

When the fluorescent hydrophobes (naphthyl group) were incorporated in the copolymer, the photophysical response may effectively probe the copolymer behavior on the microscopic level [18]. The distribution of the labels was not expected to be random, but rather that the PVP- $b$-PNT copolymers would present a blocky architecture. We can address this question with respect to the distribution of the fluorescent groups along the macromolecules to form excited-state excimers under conditions of high density labels [19]. If a polymer carries a small number of naphthyl distribution along the chain, the naphthyl*/naphthyl encounter probability will be low; hence, excimer emission will be weak compared to the monomer emission. Conversely, if the copolymer presents blocks of high naphthyl density, the contribution of naphthyl excimers to the overall emission will be high.

To make this spectroscopic tool to be used effectively, it was necessary to dissolve the labeled polymers in a good solvent to avoid solvent-induced clustering of the labeles. Here, we measured the emission of PVP- $b$-PNT in $\mathrm{CHCl}_{3}$. $\mathrm{CHCl}_{3}$ is a good solvent for all the PVP- $b$-PNT samples prepared. The emission of block naphthyl-labeled PVP samples showed only one broad emission $I_{\mathrm{E}}$, centered between 440 and $450 \mathrm{~nm}$, characteristic of naphthyl excimer emission. It should be noted that the monomer emission was not observed in PVP- $b$ PNT solutions. This phenomenon is quite different from the previous literatures on naphthyl-labeled dendrimer and random polymers $[20,21]$.

In order to investigate the chain architecture on the photophysics of copolymer, we measured the emission of the random naphthyl-labeled PVP with equal absorbance of PVP- $b$-PNT dissolved in $\mathrm{CHCl}_{3}$. The fluorescence spectrum in Figure 5 shows two major bands, one at shorter wavelength (monomer emission) with $\lambda_{\max }=375 \mathrm{~nm}$ and the other a broad but weak band at longer wavelengths (excimer emission) with $\lambda_{\max }=448 \mathrm{~nm}$. The emission of random polymer shows both monomer and excimer emission, which is different from the block polymer. The fluorescent observation results show that the copolymers with a blocky architecture tend to present strong excimer emission than random copolymer. 


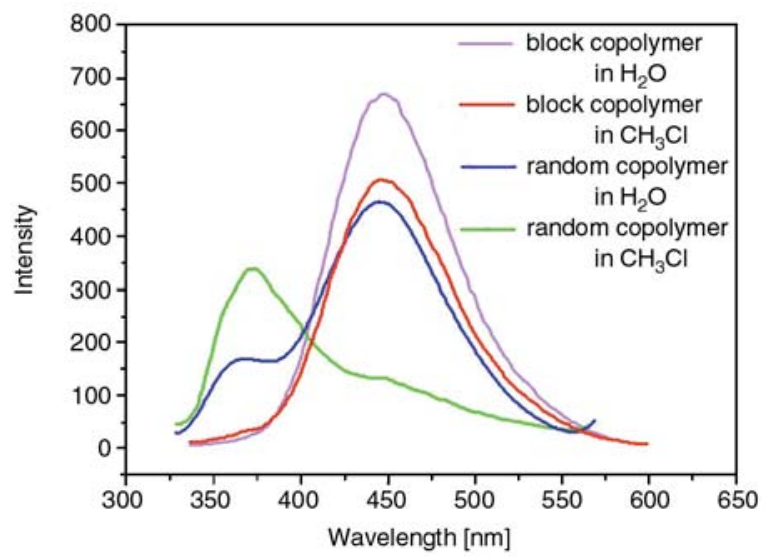

Figure 5. Fluorescence emission spectra of random and block copolymers solution at $20^{\circ} \mathrm{C}$ excited at $330 \mathrm{~nm}$. Both solutions in $\mathrm{CHCl}_{3}$ have equal absorbance $\left(\mathrm{A}_{330}=0.2\right)$

The appearances of the excimer band with maximum around $448 \mathrm{~nm}$ are observed in random and block polymers. Generally the naphthyl excimer emission is about $400 \mathrm{~nm}$, but in this case, the excimer emission wavelength of PVP- $b$-PNT and random polymer is red shifted to $448 \mathrm{~nm}$, which is due to the hydrophobic monomer chemistry structure. Naphthyl thiourea monomer has a tautomeric form, which brings a big conjugated $\pi$ bond between naphthyl and thiourea residue [22]. The special structure makes higher fluorescence efficiency and reflects the red shift in excimer emssion. A similar phenonmenon was observed in other conjugated polymers [23].

At the same time, we dissolved the random and block polymers in water, respectively. As the emission spectra recoded in Figure 2, two trends are apparent: 1. the $I_{\mathrm{E}}$ of block polymer and random polymer increase; 2 . the $I_{\mathrm{E}}$ is significantly higher of aqueous solution of block polymers, compared to the random polymers.

The block polymers exhibit stronger excimer band than that of the random polymers in both $\mathrm{CHCl}_{3}$ and aqueous media. These results suggest that inter- and intra-molecular associations facilitate excimer formation for block and random polymers. But the association ability is stronger in block polymers than in random polymers. For block polymer solution in $\mathrm{CHCl}_{3}$, the broad excimer emission $I_{\mathrm{E}}$ centering between 440 and $450 \mathrm{~nm}$ derives from intramolecular association. The intramolecular association results from interactions between the naphthyl groups within the block itself. For the block polymer solution in water, the strong excimer emission $I_{\mathrm{E}}$ comes from inter- and intra-association of block chains. Meanwhile, the intramolecular and intermolecular association results from interactions between naphthyl groups at the different chains.

\subsection{Interactions with DNA}

The blocking of the fluorescent probe into the polymer backbone provides the possibility to employ luminescent techniques at very low concentrations. The nucleotide sensing and quantification by means of luminescent probes represent an important target in supramolecular chemistry due to their many biological and biomedical implications [25]. The interaction of the PVP- $b$-PNT with DNA is described and we found the potential molecular recognition of this for DNA in aqueous solution.

Fluorimetric titrations were conducted with addition of DNA solutions. The fluorescence spectra were shown in Figure 6. The excimer emission was quenched after DNA addition. An interpretation for DNA's quenching effect could be a multitopic hydrogen bonding interaction between the hydrophobic thiourea and the DNA fragment. Bisthiourea moieties selectively bind to dihydrogenphosphate via multitopic hydrogen bonding, giving stronger complexes with $\mathrm{H}_{2} \mathrm{PO}_{4}^{-}$[24]. Naphthyl or groups bounded to polymer interact in aqueous media tend to form a sandwich-like dimeric conformation (excimer) regularly [25]. In the solution of PVP- $b$-PNT and DNA, the interaction between DNA and thiourea of polymer chain inhibits naphthyl groups to form a sandwich-like dimeric conformation which increases the excited-state energy and decreases fluorescence intensity.

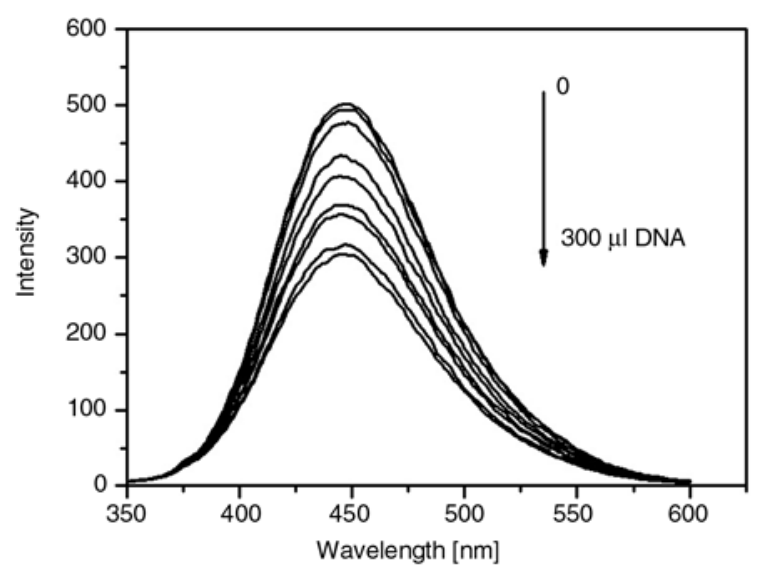

Figure 6. Fluorescence spectroscopy of PVP- $b$-PNT-III aqueous solution $\left(5 \cdot 10^{-5} \mathrm{~g} / \mathrm{ml}\right.$ in $0.05 \mathrm{M}$ Tris- $\mathrm{HCl}, \mathrm{pH}=7.4$ ) upon the addition of DNA $(0.114 \mathrm{~mol} / \mathrm{l})$ at $20^{\circ} \mathrm{C}$ excited at $330 \mathrm{~nm}$ 


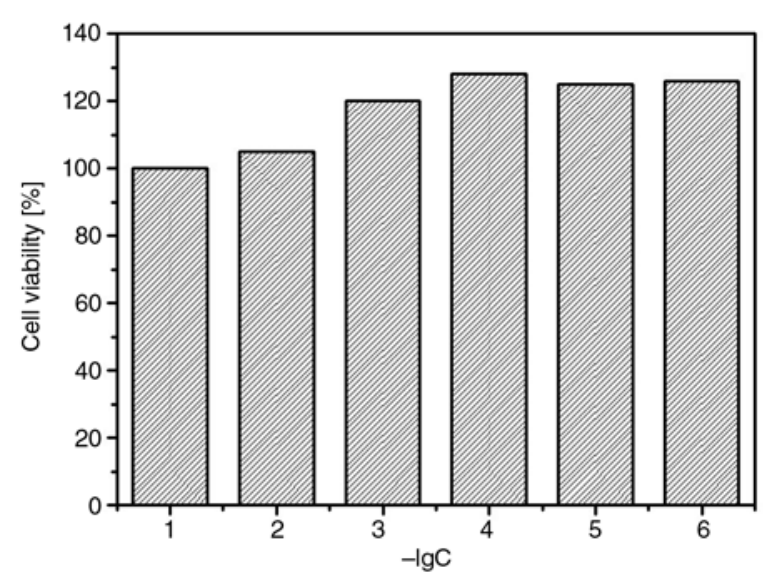

Figure 7. Cytotoxicity of PVP- $b$-PNT-III in vitro by MTT assay

\subsection{Cytotoxicity of PVP- $b$-PNT in vitro}

To determine biocompatibility of the fluorescent copolymer PVP- $b$-PNT, its cytotoxicity towards A549 cells was determined by means of the MTT assays. The effect of copolymer concentration on cell viability was illustrated in Figure 7, within experimental error, negligible, the cell viabilities being above $100 \%$ relative to a negative control at concentration of PVP- $b$-PNT-III ranging from $10^{-6}$ to $10^{-1} \mathrm{mg} / \mathrm{ml}$. In other words, solution of PVP- $b$ PNT-III has no apparent cytotoxic effect on A549 cells. This may be attributed to the biocompatibility of the hydrophilic PVP shell formed by PVP- $b$ PNT-III on self-aggregation.

\section{Conclusions}

New fluorescence copolymers PVP- $b$-PNT were synthesized by ATRP with PVP-Cl and Nmethacryloyl-N'- $\alpha$-naphthylthiourea (NT). For the block polymer solution in water, the emission of PVP- $b$-PNT samples showed only one broad emission $I_{\mathrm{E}}$, centered between 440 and $450 \mathrm{~nm}$, characteristic of naphthyl excimer. The higher excimer emission $I_{\mathrm{E}}$ comes from inter- and intra-aggregation between naphthyl groups at the different chains. DLS and TEM observation suggested block polymers in water self-assembled into spherical micelles. For block polymer solution in $\mathrm{CHCl}_{3}$, the broad excimer emission $I_{\mathrm{E}}$ derives from intramolecular association between the naphthyl groups within the block itself. Fluorescence measurements of the structurally well-defined PVP- $b$-PNT polymer can provide templates for developing a wide rang of fluorescent amphiphilic macromolecules and characterize conformational dynamics of polymer chains.

\section{Acknowledgements}

The authors are grateful to National Natural Science Foundation for financial support (Grant No. 20474044 and 20644002) and Prof. Y. Liang, Jianghan University for his help in cell cytotoxicity test.

\section{References}

[1] Gref R., Minamitake Y., Peracchia M. T., Trubetskoy V., Torchilin V., Langer R.: Biodegradable long-circulating polymeric nanospheres. Science, 263, 1600 1603 (1994).

[2] Discher D. E., Eisenberg A.: Polymer vesicles. Science, 297, 967-973 (2002).

[3] Kukula H., Schlaad H., Antonietti M., Förster S.: The formation of polymer vesicles or 'peptosomes' by polybutadiene-block-poly(l-glutamate)s in dilute aqueous solution. Journal of the American Chemical Society, 124, 1658-1663 (2002).

[4] Yusa S-I., Fukuda K., Yamamoto T., Ishihara K., Morishima Y.: Synthesis of well-defined amphiphilic block copolymers having phospholipid polymer sequences as a novel biocompatible polymer micelle reagent. Biomacromolecules, 6, 663-670 (2005).

[5] He F., Tang Y., Yu M. H., Feng F., An L. L., Sun H., Wang S., Li Y. L, Zhu D. B, Bazan G. C.: Quadruplex-to-duplex transition of g-rich oligonucleotides probed by cationic water-soluble conjugated polyelectrolytes. Journal of the American Chemical Society, 128, 6764-6765 (2006).

[6] Carvell M., Robb I. D., Small P. W.: The influence of labeling mechanisms on the fluorescence behaviour of polymers bearing fluorescein labels. Polymer, 39, 393-398 (1998).

[7] Chowdhury P., Chakravorti S.: Effect of $\mathrm{pH}$ in the photophysics of 2-hydroxy 1-naphthaldehyde in micellar systems. Journal of Photochemistry and Photobiology A: Chemistry, 179, 95-104 (2006).

[8] Haaf F., Sanner A., Straub F.: Polymer of N-vinyl pyrrolidone: synthesis, characterization and uses, Polymer Journal, 17, 143-152 (1985).

[9] Wu Z. Q., Gong S. L., Li C., Zhang Z., Huang W. H., Meng L. Z., Lu X. J. He Y. B.: Novel water-soluble fluorescent polymer containing recognition units: synthesis and interactions with PC12 cell. European Polymer Journal, 41, 1985-1992 (2005).

[10] Zhang L. F., Liang Y., Meng L. Z., Lu X. J., Liu Y. H.: Preparation and PCR-amplification properties of a novel amphiphilic poly(N-vinylpyrrolidone) (PVP) copolymer. Chemistry and Biodiversity, 4, 163-174 (2007). 
[11] Matyjaszewski K., Xia J.: Atom transfer radical polymerization. Chemistry Review, 101, 2921-2990 (2001).

[12] Li C., Lu X. J., Meng L. Z., Zhang L. F., He Y. B: Amphiphilic random copolymers based on N-isopropylacrylamide: self-aggregation behavior and interactions with nucleotides. Journal of Applied Polymer Science, 105, 2532-2539 (2007).

[13] Lu X. J., Gong S. L., Meng L. Z., Li C., Yang S., Zhang L. F: Controllable synthesis of poly(N-vinylpyrrolidone) and its block copolymers by atom transfer radical polymerization. Polymer, 48, 2835-2842 (2007).

[14] Mosmann T.: Rapid colorimetric assay for cellular growth and cytotoxic assays. The Journal of Immunological Methods, 65, 55-63 (1983).

[15] Huang J., Matyjaszewski K.: Atom transfer radical polymerization of dimethyl(1-ethoxycarbonyl)vinyl phosphate and corresponding block copolymers. Macromolecules, 38, 577-3583 (2005).

[16] Jewrajka S. K., Mandal B. M.: Living radical polymerization. 1. The case of atom transfer radical polymerization of acrylamide in aqueous-based medium. Macromolecules, 36, 311-317 (2003).

[17] Winnik F. M.: Fluorescence studies of aqueous solutions of poly( $\mathrm{N}$-isopropylacrylamide) below and above their LCST. Macromolecules, 23, 233-242 (1990).

[18] Liaw D. J., Huang C. C., Sang H. C., Kang E. T.: Intramolecular hydrophobic aggregation of amphiphilic polysulfobetaine with various hydrophobic groups in aqueous solution. Langmuir, 15, 5204- 5211 (1999).
[19] Lankkanen A., Winnik F. M., Tenhu H.: Pyrenelabeled graft copolymers of $\mathrm{N}$-vinylcaprolactam: synthesis and solution properties in water. Macromolecules, 38, 2439-2488 (2005).

[20] Ghaddar T. H., Whitesell J. K., Fox M. A.: Excimer formation in a naphthalene-labeled dendrimer. Journal of Physics Chemistry: B, 105, 8729-8731 (2001).

[21] McCormick C. L., Hoyle C. E., Clark M. D.: Watersoluble copolymers. 35. Photophysical and rheological studies of the copolymer of methacrylic acid with 2-(1-naphthylacetyl)ethyl acrylate. Macromolecules, 23, 3124-3129 (1990).

[22] Li C., Meng L. Z., Lu X. J., Wu Z. Q., Zhang L. F., He Y. B.: Thermo- and $\mathrm{pH}$-sensitivities of thiosemicarbazone-incorporated, fluorescent and amphiphilic poly(N-isopropylacrylamide). Macromolecular Chemistry and Physics, 206, 1870-1877 (2005).

[23] Fox M. A., Thompson H. W.: Synthesis and photophysical characterization of group transfer polymers with pendent aryl chromophores. Macromolecules, 30, 7391-7396 (1997).

[24] Buhlmann P., Nishizawa S., Xiao K., Umezawa Y.: Strong hydrogen bond-mediated complexation of $\mathrm{H}_{2} \mathrm{PO}_{4}$ ( by neutral bis-thiourea hosts. Tetrahedron, 53, 1647-1654 (1997).

[25] Kramer M. C., Welch C. G., Steger J. R., McCormick C. L.: Water-soluble copolymers. 63. rheological and photophysical studies on the associative properties of pyrene-labeled poly[acrylamide-co-sodium 11-(acrylamido)undecanoate]. Macromolecules, 28, 52485254 (1995). 